\title{
An SVC controller for Power Quality Improvement of a Heavily Loaded Grid
}

\author{
Faheem Ali ${ }^{1}$, Muhammad Naeem Arbab ${ }^{1}$, Gulzar Ahmad $^{1}$, Majid Ashraf ${ }^{1}$, \\ Muhammad Sarim²
}

RECEIVED ON 16.11.2018, ACCEPTED ON 19.02.2019

\begin{abstract}
Pakistan is faced with energy crises from the last two decades. Generation cannot balance the load demands of the electricity consumers. Power delivery systems are generally old-fashioned and overloaded. They are unable to provide consistent and uninterrupted supply to commercial, industrial, and domestic loads. Generally speaking, the Power Systems consist of loads that are inductive and resistive in nature. Heavy machinery, induction motors, and arc furnaces are heavily inductive in nature. Inductive loads when operated in a weak power system results in lagging VARs (Volt Ampere Reactive) and poor voltage regulation, which must be balanced by the same number of leading VARs in order to ensure unity power factor and thus helps in improving the voltage profile. At times the reactive VARs injected may not be sufficient to balance the VARs requires by the system, but still the power factor is improved up to some extent. In hot and humid climatic conditions, air-cooling system and chillers greatly burdens the grids. Such loads require excessive reactive VARs, and if not offered with ample reactive power, causes severe voltage drops in distribution system. To manage low voltages and power-factor, household users use automatic voltage regulators while industries connect capacitor banks. Voltage regulators control output voltage within the required limits at the expense of excessive line current from transformer, which may overburden it. Moreover, with each operation of tap changer, current rises which further intensifies line losses. Static capacitors provide stable voltage but repeated variations in load demands reliable and vigorous voltage regulation. This investigation aims to come up with a power quality improvement scheme which would deliver instantaneous control of power (reactive) with SVC (Static VAR Compensator) thus overcoming the shortcomings of step-wise banks of capacitors and or voltage regulators. Simulation work is carried out in MATLAB/SIMULINK and the results are compliance with IEEE Standards for SVCs. The device can offer steady state as well as dynamic VAR compensation under changing load conditions. Result showed considerable improvement both in terms of response time and power factor. Switching time has been improved to less than 1/10th fraction of a second which in previous simulations was 0.7 seconds approximately. Initial power factor without disturbance and without compensation was recorded to be 0.6 lagging, which after compensation was improved to 0.95 lagging. Similarly, in presence of disturbance without compensation the power factor fluctuated between 0.55 and 0.9 lagging, which after compensation was improved to 0.95 lagging and above throughout the course of operation.
\end{abstract}

Key Words: Flexible AC Transmission System, Power Factor Improvement, Power Quality Improvement, Static Volt Ampere Reactive Compensator.

\footnotetext{
${ }^{1}$ Department of Electrical Engineering, University of Engineering and Technology, Peshawar, Pakistan Email: faheem@uetpeshawar.edu.pk (Corresponding Author), mnarbab@yahoo.com, Gulzar@uetpeshawar.edu.pk, majid@uetpeshawar.edu.pk ${ }^{2}$ Federal Urdu University of Science, Arts and Technology, Karachi, Pakistan. Email: msarim@ fuuast.edu.pk
}

This is an open access article published by Mehran University of Engineering and Technology, Jamshoro under CC BY 4.0 International License. 


\section{INTRODUCTION}

The reforms initiated in Pakistan in early 90's was a complete failure and resulted a crisis in power sector. As a result, the country is presently facing a severe and multifaceted energy crisis. The load shedding conditions across the country is a major barrier in industrial growth and sustainability of the sector. The problem is partially due to chronic losses, outdated and overstressed power transmission and distribution networks [1]. As a result, most of the distribution feeders experience low voltage and poor power factor. The poor power factor increases the losses in the distribution system because the equipment draws higher current at lower power factor which may damage the equipment. Moreover, the utility companies impose penalties on such consumers. In order to deal with the complications, house hold users use automatic voltage regulators and industrial users frequently fit capacitor sets. The voltage stabilizers draw increased line current from the distribution transformer to regulate the output voltage within specified limits, which may cause the saturation and overloading in the distribution transformer. Although capacitor banks can provide good steady state voltage regulation, frequent load variation in industries requires more reliable, dynamic and fast voltage regulation [2].

Various types of compensation methods are being used in the power network to improve power factor. FACTS (Flexible AC Transmission System) are good for compensation at both low and elevated temperatures but are slower in response. Power factor correction devices along with solid state power electronic switches were used for improving power quality and thus switching time was improved as electro mechanical relays were replaced by high speed power electronic switches [3]. Investigations were carried out regarding controllers for real time power factor improvement using high speed electronics switches. Controllers were designed, investigated and tested, and recommendations were made based of the results [4]. FACTS are good at compensation at both low and elevated temperatures but are slower in response [5]. SVC can address the changing active and reactive power requirements (dynamic load conditions). By controlling the firing angle of thyristor, the reactive power injection from the SVCs can be controlled [6]. In order to withstand higher voltages, the series connected SCRs can be increased adding up the voltage withstanding capabilities. In case of leading power factor scenario because of lightly loaded situations, TCR's were used to absorb the reactive power so as to balance it helping the system to be maintained near unity power factor [7]. In order to bring in controllability of two-way switches Gate Turn Off Thyristors were introduced [8]. Harmonic filters when added to TSC's and TCR's would reduce the harmonics introduced in to the system because of switching [9].

This paper targets to develop a power quality enhancement scheme which is capable of delivering reactive power with instantaneous control using Power Electronic (solid state) and FACTS devices consequently disregarding the electro-mechanical relays. The suggested device is able to feed leading VARs (Capacitive) in changing load conditions thus balancing Reactive Power $(\mathrm{Q})$ of the system in a weak grid. The commitment of this analysis is to improve efficiency and ease grid overburdening. Moreover, this research investigates the controllers for designing SVC for spontaneous control of Q using PE devices as switches. It develops a scheme of power factor improvement for industrial users so that the voltages are confined within permissible limits and system performance is improved. The scheme is rigid enough to work under stressful conditions. Extensive simulations are performed in MATLAB/SIMULINK to test the effectiveness of the developed device and the results are compliance with IEEE Standards for SVC's. The vice can offer both static and dynamic compensation under fluctuating load conditions.

\section{METHODS OF POWER FACTOR CORRECTION}

\subsection{Static Capacitors}

Previously static capacitors were used for power factor correction. The problem with static capacitors was in case of varying loads where surges were caused by capacitor banks. Also, step less control was not possible because of discrete capacitances only capable of providing correction in steps.

Mehran University Research Journal of Engineering and Technology, Vol. 39, No. 2, April 2020 [p-ISSN: 0254-7821, e-ISSN: 2413-7219] 


\subsection{Synchronous Condensers}

It helps in providing varying VARs in to the system, but the limitations were less efficiency, higher losses because of rotating parts, and high cost. Also, synchronous motors need auxiliary equipment for staring purposes.

\subsection{Phase Advancers}

Phase advancers were used for the power quality improvement with the limitations of cost in case of low power applications.

\subsection{Flexible Alternating Current Transmission Systems}

The latest trends in power quality improvement is the use of FACTS controllers for power factor correction. Though it has been widely used as an approach for power factor correction, still improvements are possible with introduction of fast power electronic switches and alteration in firing angle controls.

Previously TSC where used in connection with TCR in order to improve power factor in real-time. Now in order to control harmonics and improve system response, I have introduced a power correction scheme that uses TCR with fixed capacitors. In this approach power factor could be controlled in real time as well as harmonics are kept at minimum, which is obvious from the results.

Table 1 shows the comparison between TSC with TCR and TSC with Fixed Capacitors. The response time is reduced from 0.7 seconds to 0.01 seconds. Power factor improvement is in the same range. Voltage variation is well within permissible limits. Reactive
Power is fully Compensated which had huge transients in the previous work.

\section{STATIC VAR COMPENSATOR}

One of the 1st generation FACTS device is a Static VAR Compensation, which was first used in an Electronic corporation in the second last decade of 20th Century. It is meant for compensation both in terms of voltage stability and reactive power [10]. Normally it is connected in parallel across the load in a power system at weak locations. The reactive compensation helps in maintaining constant voltage at different points on power system. They could be broadly classified as under:

TSC (Thyristor Switched Capacitors)

TCR (Thyristor Controlled Reactor)

TSR and TCR (Combination of Both)

\subsection{Thyristor Switched Capacitor}

It is the series combination of bidirectional controlled valve made of two anti-parallel thyristors with a series connected capacitor. At times, an inductor is added in series with capacitor for limiting the rate of change of current. TSC (Thyristor Switched Capacitor) could be installed in delta or star configuration at suitable location on power system [11]. If operated with controlled triggering the need of harmonic filter could be suppressed because of negligible harmonics being produced, making it a cost-effective solution. The VAR injection is again in steps, as it could be either fully ON or OFF. The disadvantage when operated in controlled mode is the introduction of excessive harmonics in the system. Overheating is caused as a

\begin{tabular}{|c|c|c|c|c|c|}
\hline \multicolumn{6}{|c|}{ TABLE 1. COMPARISON BETWEEN TSC WITH TCR AND TSC WITH FIXED CAPACITORS } \\
\hline References & $\begin{array}{c}\text { Response } \\
\text { Time } \\
(\mathrm{Sec})\end{array}$ & $\begin{array}{c}\text { Power } \\
\text { Factor }\end{array}$ & $\begin{array}{c}\text { Voltage } \\
\text { Regulation }\end{array}$ & $\begin{array}{c}\text { Reactive } \\
\text { Power }\end{array}$ & Remarks \\
\hline$[8]$ & 0.7 & $0.95-1$ & $\begin{array}{c}\text { Not } \\
\text { Mentioned }\end{array}$ & $\begin{array}{c}\text { Huge } \\
\text { Transients 45 } \\
\text { MVAR (0.4- } \\
0.8 \text { sec) }\end{array}$ & $\begin{array}{c}\text { Response is slow, Voltage Regulation not } \\
\text { Mentioned, Huge Transients }\end{array}$ \\
\hline This Work & 0.01 & $0.95-1$ & $\begin{array}{c}\text { Less than } \\
10 \%\end{array}$ & $\begin{array}{c}\text { Fully } \\
\text { Compensated }\end{array}$ & $\begin{array}{c}\text { Q fully Compensated, p. f. high, Regulation } \\
\text { within range, response time considerably } \\
\text { improved }\end{array}$ \\
\hline \hline
\end{tabular}


result that would affect TSC performance. Blocking and deblocking of a Thyristor switched capacitor is made possible with the help of SCR (Silicon Controlled Rectifiers). Transitions are smoother when turn-on happens at minimum voltage across the device. The voltage experienced by a reversed biased switch is twice that of the supply voltage, thus devices of appropriate ratings must be installed so that to avoid any unforeseen situations or breakdowns [12]. Devices could be added in series so that to withstand reverse voltages. Harmonics are maximum when an SCR is triggered as maximum voltage, the situation is known as misfiring. In such scenarios capacitors might get over charged thus resulting in transients in the system. Excessive currents might damage the valves/devices resulting in failure of TSCA typical TSC branch is shown in Fig. 1.

\subsubsection{TSC Modelling}

TSC is connected in delta fashion to reduce harmonics, each branch consisting of bi-directional valve, capacitor, and filter inductor. The rating of the thyristor is based on the voltage it is going to experience during the course of operation. Filter inductors $\mathrm{L}_{\mathrm{ab}}, \mathrm{L}_{\mathrm{bc}}$, and $\mathrm{L}_{\mathrm{ca}}$ are added inductances to limit the rate of change of current. Capacitor is a design parameter and requires special attention as the injection of VARs is strictly dependent upon it. The value of capacitance in TSC branch can be computed using Equation (1).

$\mathrm{C}=\frac{\mathrm{kVAR}(\mathrm{C}) \times 1000}{2 \pi \mathrm{fV}^{2}}$

Here, $\mathrm{f}$ is the system frequency, $\mathrm{C}$ represent the total capacitance required for maximum VARs injection, $\operatorname{kVAR}(\mathrm{C})$, represent maximum capacitive VARs to be provided.

Thus, by fixing the value of $\mathrm{C}$, the design parameter is limited to provide the maximum VAR's required by each TSC branch. Thus, by fixing the value of $\mathrm{C}$, the design parameter is limited to provide the maximum VAR's required by each TSC branch.

\subsection{Thyristor Controlled Reactor}

TCR (Thyristor Controlled Reactor) as shown in Fig. 2. It is the series combination of bidirectional controlled valve made of two anti-parallel thyristors with a series connected Inductor. Normally the inductor is split in to two equal halves connected on either side of the valve. This helps in controlling the
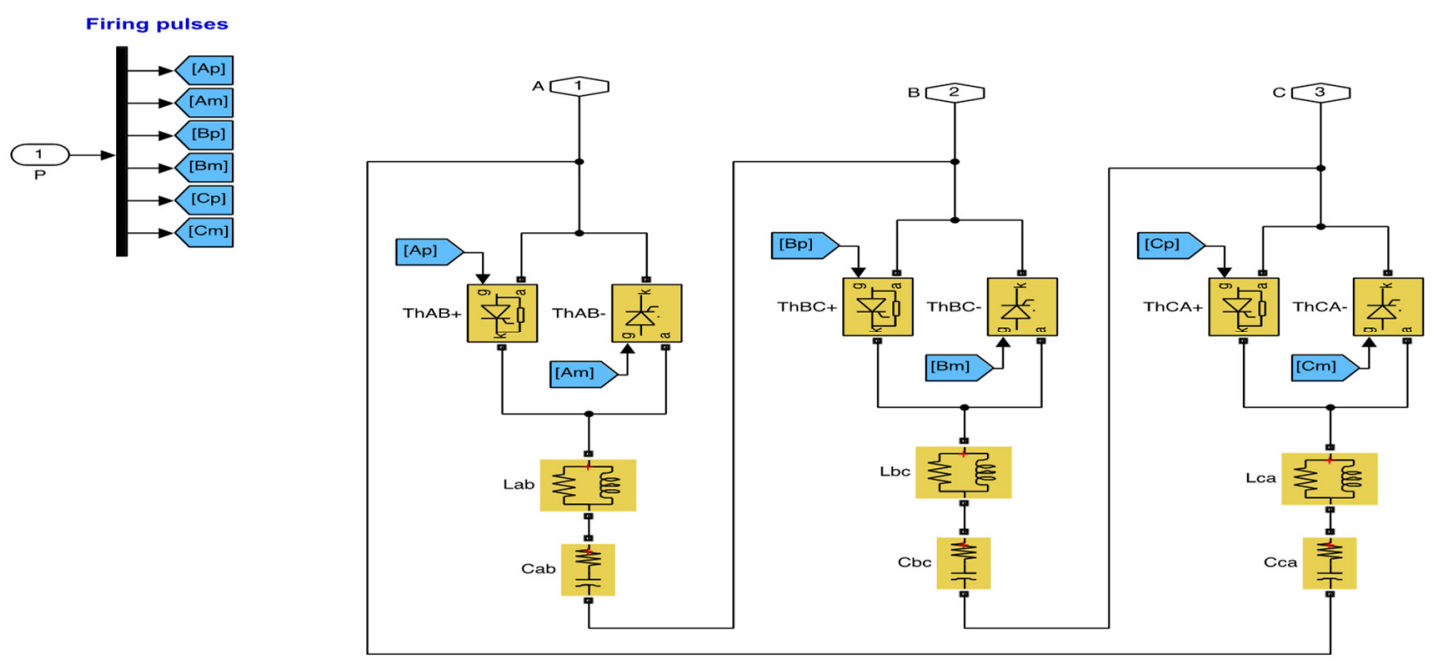

FIG 1: THYRISTOR SWITCHED CAPACITOR 

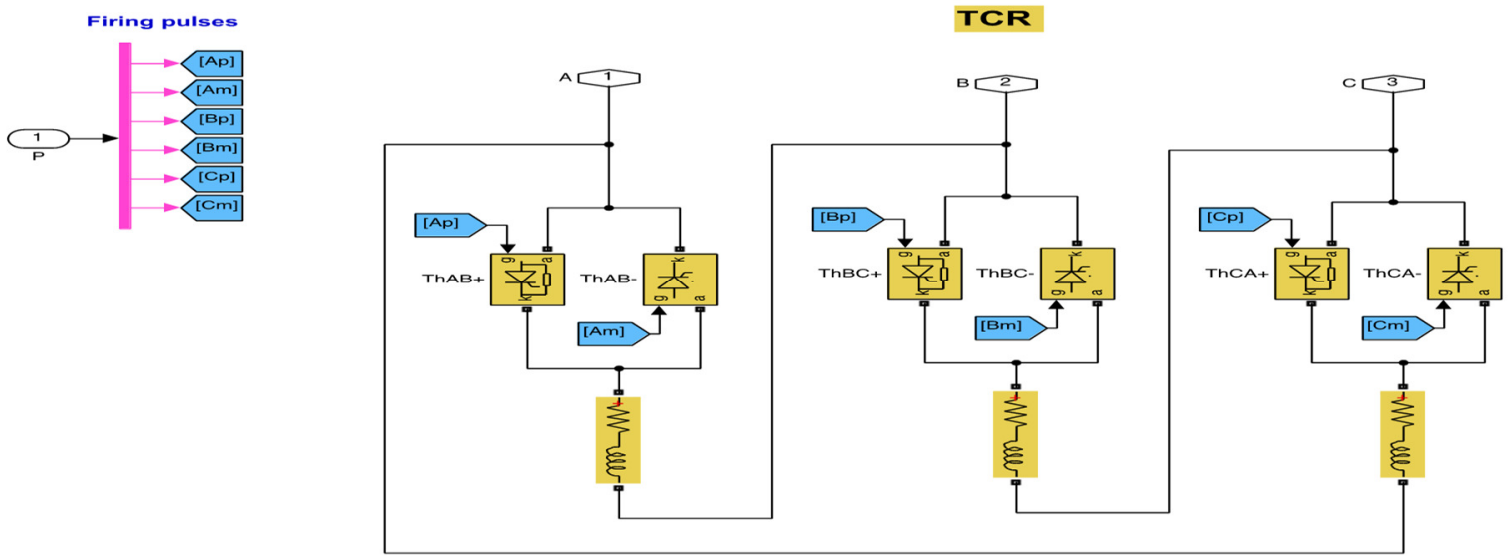

FIG. 2. THYRISTOR CONTROLLED REACTOR

the rate of changes in addition to VARs absorption. Mode of operation is phase control, where the firing pulses of the SCR are advanced or delayed so as to absorb the required number of VARs. The anti-parallel configuration introduces bi-directional control [13]. Firing angle is defined as the point of at which firing pulses are provided to a controlled switched. Normally the range of alpha is between zero and 180 degrees, where zero-degree firing operation is analogous to that of an uncontrolled switch. A power system when under loaded may give objectionable rise of voltages at the receiving end of the system. This causes load flow problems which are undesirable. In such situations, TSR is helpful in absorbing excess VARs so as to bring the power system voltage to normal position. In order to minimize harmonic distortion, it is recommended to make connections of TCR in delta. If Total Harmonic Distortion is still not within the desired range, harmonic filters could be helpful.

\subsubsection{TCR Modelling}

Similarly, in a TCR Inductor is the design parameter and needs to be fixed for maximum VAR absorbing capability. TCR is connected in delta fashion in order to reduce harmonics. Inductance of each branch in

$$
\mathrm{L}=\frac{\mathrm{V}^{2}}{2(1000 \times 2 \pi \mathrm{f} \times \mathrm{KVAR}(\mathrm{L}))}
$$

Here, $\mathrm{f}$ is the system frequency, L, represent total Inductance needed for maximum reactive VAR absorption, $\mathrm{kVAR}(\mathrm{L})$, represent maximum inductive VARs to be provided.

This value of $\mathrm{L}$ is fixed for each branch so as to absorb maximum vars. The thyristor valve controls the VAR injection to bring in controllability and to exactly meet the demand.

\subsection{Combined Operation (TSC + TCR)}

TCR when used in combination with TSC and some filters characterizes a SVARC. Combination of TCR and TSC imparts flexibility in to the system, enabling the system to respond to both leading and lagging power factor scenarios. SVC is capable of injection and well as absorption of VARs. A compensator when directly installed of line voltage reduces cabling requirements because of elimination of a coupling transformer. 


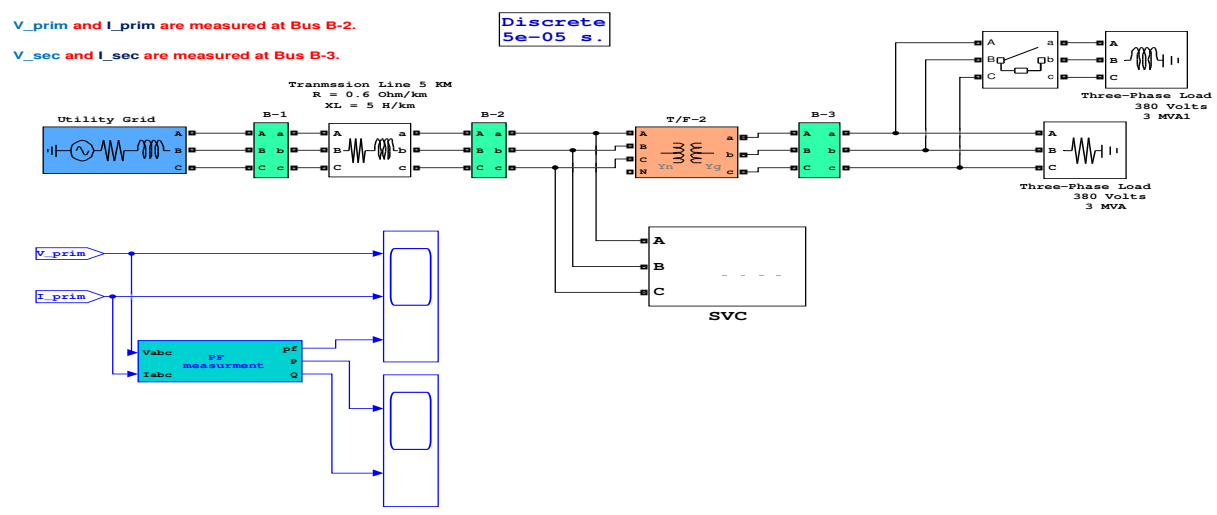

FIG. 3. POWER SYSTEM WITH STATIC VAR COMPENSATION

\section{DESIGNING OF STATIC VAR COMPENSATOR}

A power system is shown in the Fig..3. X/R ratio is so adjusted to represent a weak bus system. SVC is connected on $11 \mathrm{kV}$ side. A resistive load is connected in addition to an inductive load connected to low tension side through three phase circuit breakers. Primary voltages and currents are measured at busbar 2 , secondary voltages and currents are measured at bus 3. A power factor computing unit is shown in the background. A couple of scopes are connected; one showing plots for voltage, current, and power factor, other showing active power $\mathrm{P}$ and reactive power $\mathrm{Q}$.

SVC controller is the most crucial component of the model which helps in balancing the lagging VAR's by adjusting the control angle of thyristors in different TSC Blocks. It measures the lagging VAR's at the output and adjust firing angle accordingly to control capacitor current and thus controls the VAR's injected into the system. The SVC controller consists of different sub blocks (Distribution Unit, Firing Unit, Pulse Generator). Fig. 4 shows three TSC blocks and one TCR Block, each TSC block capable of providing
MVAR support. Whereas Fig.5 shows sub blocks of SVC controller.

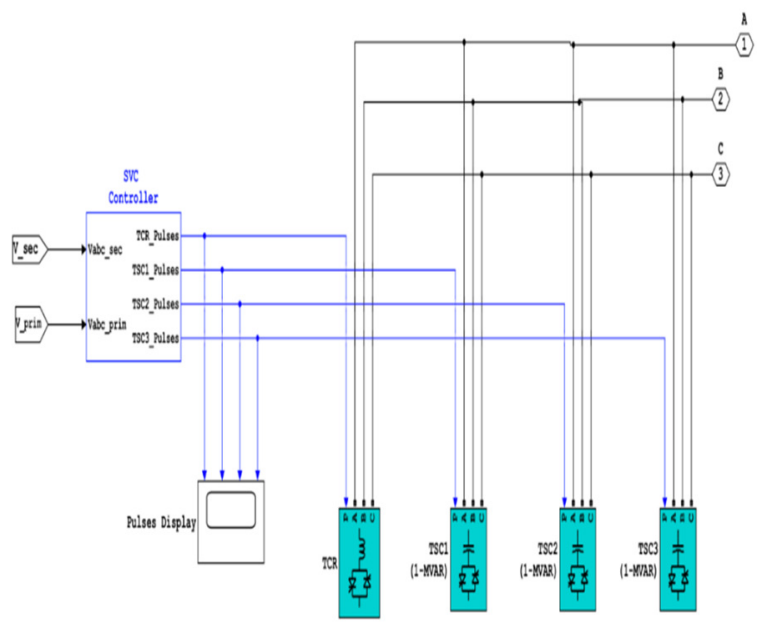

FIG. 4. INSIDE VIEW OF SVC CONTROLLER

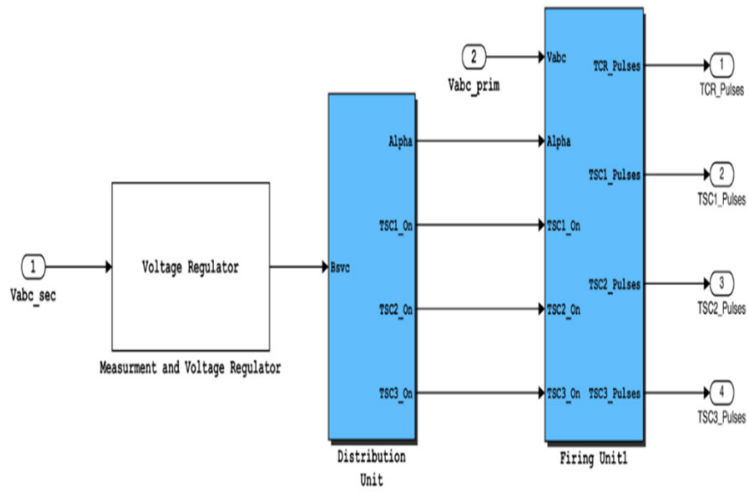

FIG. 5: SUB BLOCK OF SVC CONTROLLER 


\subsection{Distributing Unit}

A distribution unit is shown in Fig.6. It helps in determining the values of alpha for each thyristor valve. It also ensures whether a single unit is sufficient to cope with the situation or other units are required to switch in.

There are three blocks of TSC, capability of each being 1 MVAR. If the required support is up to 1 MVAR only one-unit responds, similarly if the range is between 1 and 2 MVAR, two of the units responds, both taking equal burden in terms of support. e.g. if 1.6 MVAR support is required, 0.8 MVAR would be share of each unit. Similarly, three units would respond if the required VAR range is between 2 and 3 MVAR. A similar analysis is applicable in case of leading system VARs when TCR switches in. Firing angle, State of the switch is decided by DU. Signals are sent accordingly to generate triggering pulses.

\subsection{Firing Unit}

Firing unit sends triggering pulses to all the SCR whether connected in TCR or TSC branches. Three pulse generators as shown in Fig.7 are part of the firing unit namely firing unit $\mathrm{AB}, \mathrm{BC}$, and $\mathrm{CA}$. These generators send required pulses to all TSC branches along with TCR branch. GTO could be turned on and off using a gate pulse, whereas Thyristor could be only turned on using a gate pulse. In order to turn it off the current is supposed to be reduced below the holding current level. It is because of the circuit characteristics that the thyristor remains on for positive cycle and turns off with polarity reversal. It is for this reason that a bidirectional valve is required, one Thyristor conducting for positive cycle of the supply and the other for negative cycle of the supply. TCR+ and TSC+ represents positive gating signals, for the thyristors that are forward biased for positive cycle of the input voltage. gating signal is generated for positive cycle of voltage. Similarly, TCR- or TSC- represents negative gating signals, for the thyristors that are forward biased for negative cycle of the input voltage. Gating signals either latch in or latch out TCR or TSC.

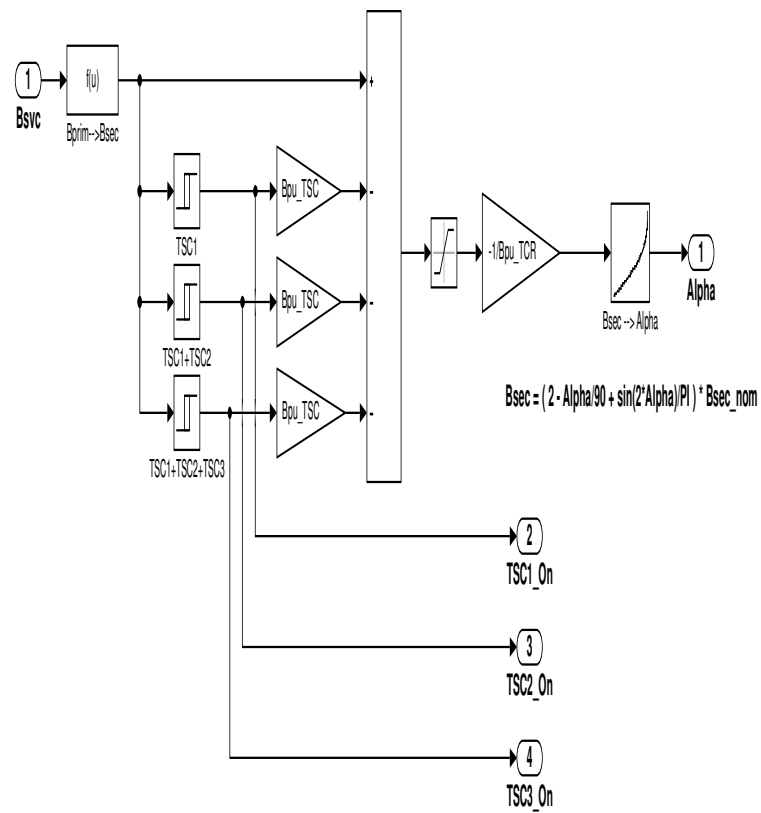

FIG. 6: DISTRIBUTION UNIT

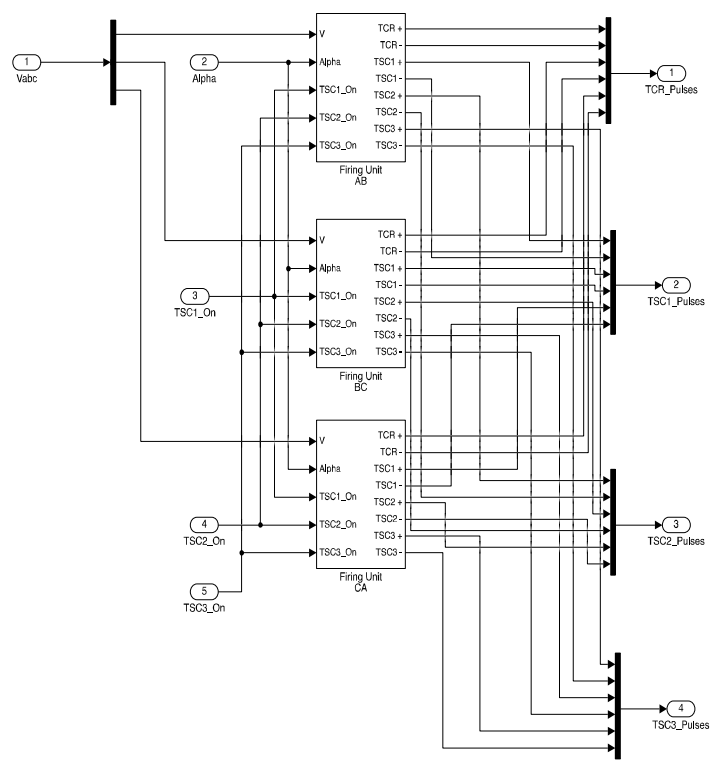

FIG. 7: FIRING UNIT 


\section{RESULTS}

All the graphs show three phase voltages and currents in the corresponding phases shown in blue, red, and green. Voltages and currents are measured in per units. Third parameter is the power factor which is shown in red. First two graphs are without real time disturbance whereas the last two are with real time inductive load introduced as disturbance between 0.3 seconds and 0.6 seconds.

Fig. 8 shows the waveforms of voltage and current in per unit along with the power factor of the uncompensated system. It can be observed that power factor is low (0.6 lagging, In the penalty zone) along with poor voltage profile. The voltage is maintained at 0.5 per unit, thus resulting in poor voltage regulation.

Fig.9 represents the same quantities after compensation. It could be seen that the power factor is compensated within a fraction of second, also the voltage profile is improved. This switching time is reduced by introduction of real time control system. Previously look up table techniques were used which were time consuming. The response time could help in supporting life span of equipment. Power factor was improved from 0.6 lagging to 0.95 lagging whereas switching time has been reduced to $1 / 10^{\text {th }}$ fraction of a second.
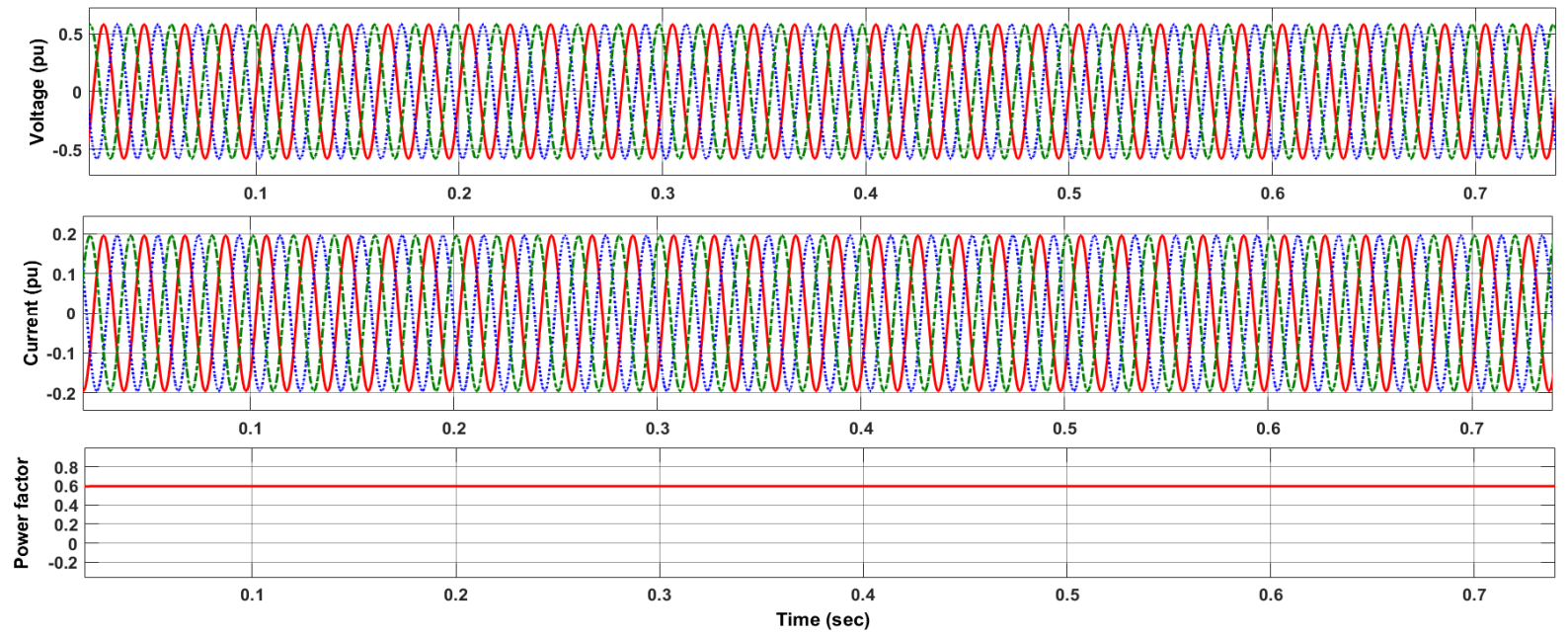

FIG. 8. VOLTAGE, CURRENT, AND POWER FACTOR PLOTS WITHOUT SVC (UN-COMPENSATED)
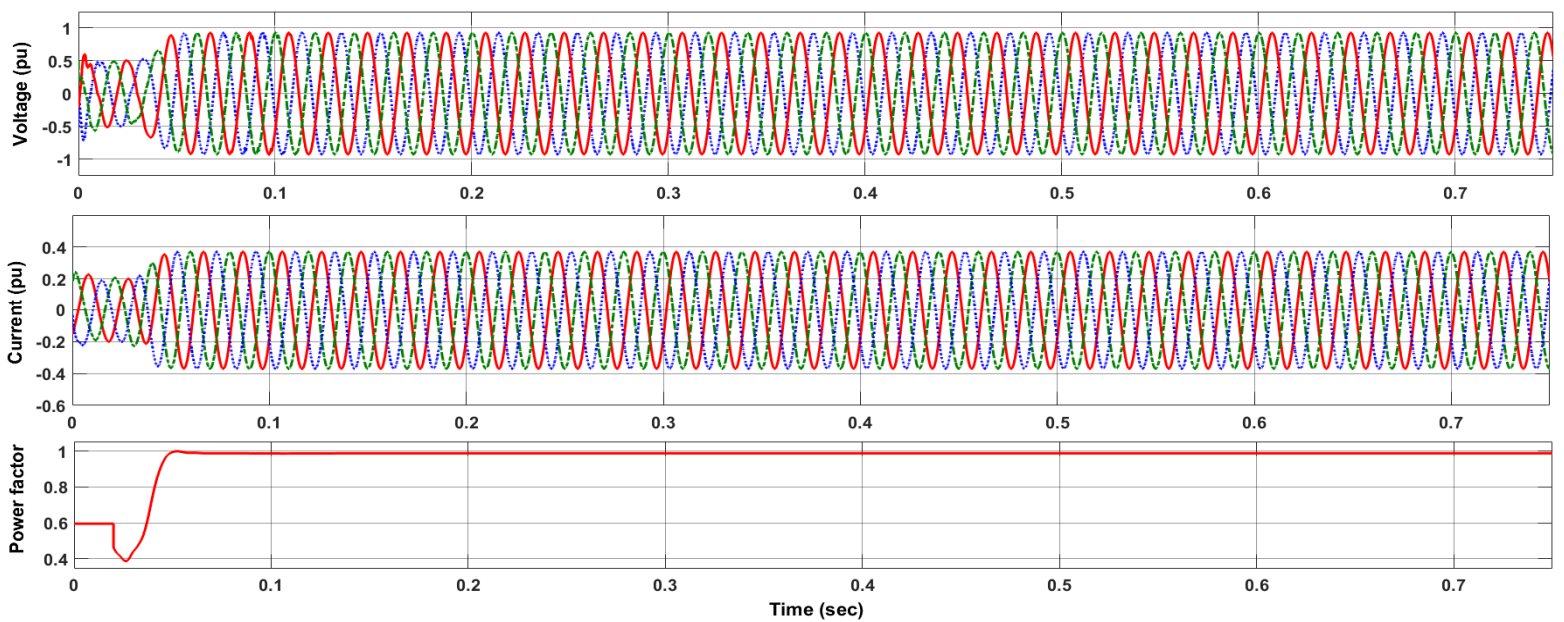

FIG. 9. VOLTAGE, CURRENT, AND POWER FACTOR PLOTS WITH SVC (COMPENSATED) 
Real time disturbance is introduced in to the system as shown in Fig.10. Initially the system is being operated as an uncompensated system, later on at $\mathrm{t}=0.3$ seconds an inductive load is being introduced causing the power factor to be very low. The disturbance is kept for 0.3 seconds and opted out at $\mathrm{t}=0.6$ seconds. It can be seen that Voltage is initially around 0.75 per unit and after the introduction of disturbance it further degrades to around 0.6 per unit thus affecting the system performance. It is understandable that as the disturbance is introduce power factor drops from 0.8 to 0.55 lagging and voltage is reduced to 0.75 per unit from 1 per unit.

Now, as SVC is introduced so as to compensate the system VAR requirement as shown in Fig.11. It is obvious that initially the power factor is improved to unity within 0.05 seconds and later on when a disturbance is introduced the uncompensated power factor of 0.55 is improved to 0.95 lagging. Voltage profile is reinstated to 0.9 per unit from its lower value of 0.75 per unit. The voltage is kept within permissible limits and the response time is fairly improved.

\section{CONCLUSION}

SVC's improved the results with the limitation of introduction of harmonics in to the system. Though harmonics could not be completely eliminated but were considerably reduced. Switching has been improved with the help of real-time control system based alpha selection instead of inspecting lookup tables. Voltage controlled switches could replace current controlled switches with the ease of simpler driving circuits, but with their own limitations in SVC design.

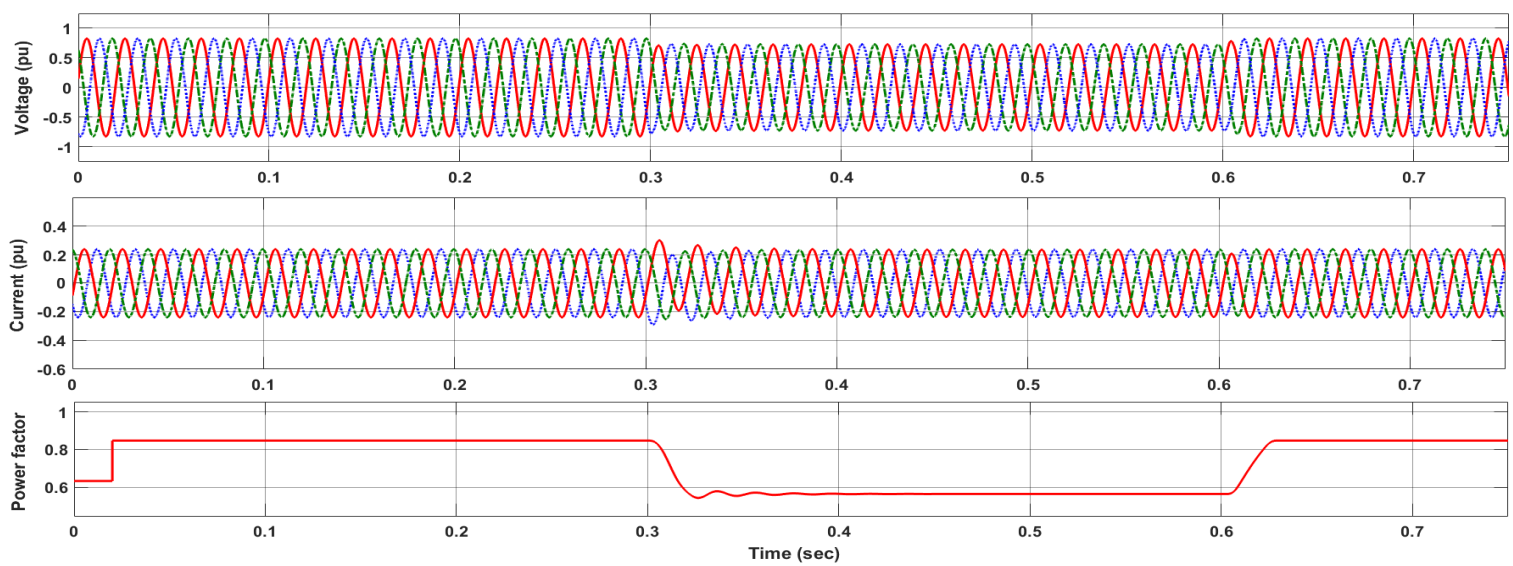

FIG. 10. REAL TIME VOLTAGE, CURRENT, AND POWER FACTOR PLOTS WITHOUT SVC (UNCOMPENSATED)

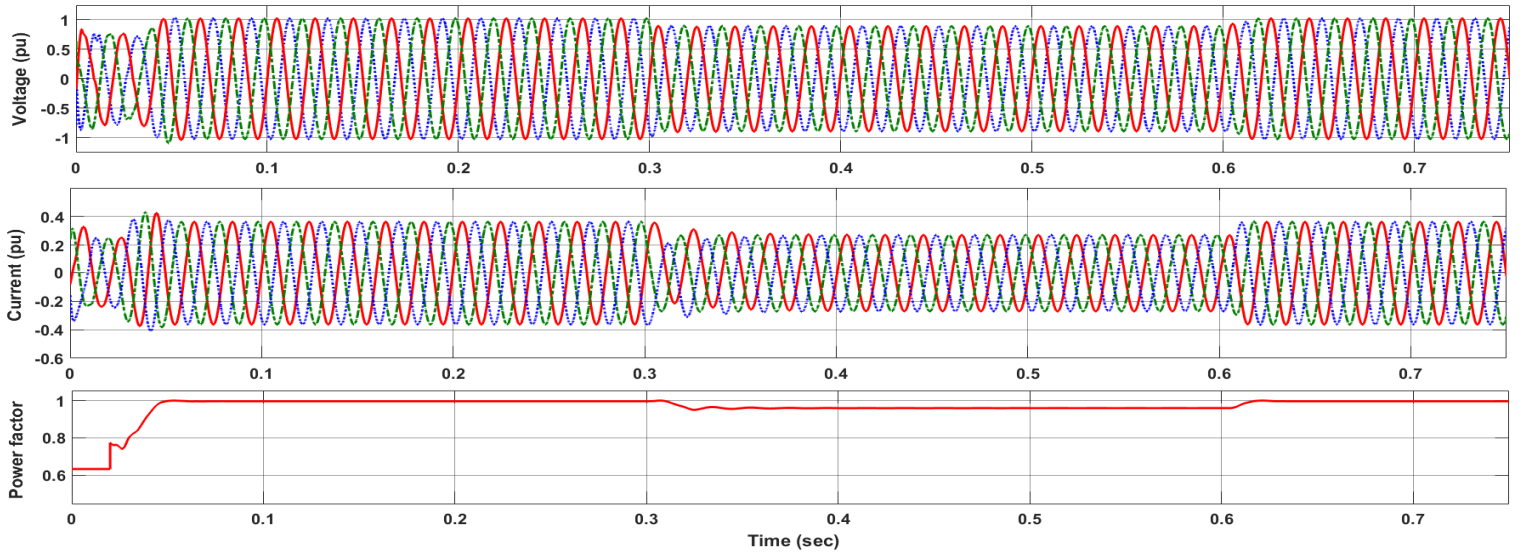

FIG. 11. REAL TIME VOLTAGE, CURRENT, AND POWER FACTOR PLOTS WITH SVC (COMPENSATED)

Mehran University Research Journal of Engineering and Technology, Vol. 39, No. 2, April 2020 [p-ISSN: 0254-7821, e-ISSN: 2413-7219] 


\section{ACKNOWLEDGMENT}

Authors would like to thank all the faculty members and supporting staff for their unconditional support throughout the research and model development.

\section{REFERENCES}

[1] Khan, A.J., "Structure and Regulation of the Electricity Networks in Pakistan", The Pakistan Development Review, Pakistan Institute of Development Economics, Vol. 53, No. 4, pp. 505-530, 2014.

[2] Sorensen, P.E., Madson, P.H., Vikkelso, A., Jensen K.K., Fathima, K.A., Unnikrishnan, A.K., and Lakaparampil, Z.V., "Power Quality and Integration of Wind Farms in Weak Grids in Indian", RISO Technical University of Denmark, Chapter 1, Page No. 7, 2000.

[3] Schipman, K., and Delince, F., "The Importance of good Power Quality", ABB Power Quality Products, Belgium, 2018. http://powermore.vn/files/doccument/power $\% 20$ quality $\% 20$ improvement $\% 20$ with $\% 201 \mathrm{v}$ \%20capacitors\%20and\%20filters.pdf accessed on 26/02/2018 at 1155PST.

[4] Ponnle, A.A., "Performance of Domestic AC Voltage Stabilizers in Meeting Low Voltage Problems in Nigeria: A Case Study of 12 Different Brands", International Journal of Engineering and Technology, Vol. 5, No. 6, pp. 358-367, 2015.

[5] Pradhan, P.C., Ray, P.K., Sahu, R.K., and Moharana, J.K., "Performance of FACTS Controller for Power Quality Improvement in a Distribution Supply System”, International Journal of Advanced Research in Electrical, Electronics and Instrumentation Energy, Vol. 3, No. 6, pp. 10019-10029, 2014.
[6] Sreenivasulu, K., and Basha, G.S., "Enhancement of Voltage Stability in Power System with Optimal Location of Static VAR Compensator", International Journal of Advanced Research in Electrical, Electronics and Instrumentation Engineering, Vol. 2, No. 7, pp. 3049-3056, 2013.

[7] Reid, W.E., "Power Quality Issues-Standards and Guidelines", IEEE Transactions on Industry Applications, Vol. 32, No. 3, pp. 625-632, 1996.

[8] Khan, M.K., Basit, A., and Ali, F., "Static VAR Compensator for Weak Grid Systems", International Journal of Engineering Works, Vol. 5, No. 1, pp. 10-15, 2018.

[9] Hart, D.W., "Power Electronics", 1st Edition, McGraw-Hill Publishers, Indiana, USA, Chapter 5, pp. 192, 2011.

[10] Kahnt, R., "The Development of High Voltage Engineering - 100 Years of AC Power Transmission", Elektrizitätswirtschaft, Volume 90, No. 11, pp. 558-576, 1991.

[11] Jalali, S.G., Lasseter, R.H., and Dobson, I., "Dynamic Response of a Thyristor Controlled Switched Capacitor", IEEE Transactions on Power Delivery, Vol. 9, No. 3, pp. 1609-1615, 1994.

[12] Jalali, S.G., Dobson, I., and Lasseter, R.H., "Instabilities Due to Bifurcation of Switching Times in a Thyristor-Controlled Reactor", 23rd Annual IEEE Power Electronics Specialists Conference (Published PESC 92 Accord), pp. 546-552, $2^{\text {th }}$ June- $3^{\text {rd }}$ July, 1992.

[13] Haque, S.E., and Shepherd, W., "Power Factor Improvement of Thyristor-Controlled Inductive Load Using an FC-TCR Compensator", IEE Third International Conference on 'Sources and Effects of Power System Disturbances, 5-7 $7^{\text {th }}$ May, London, England, 1982. 